\title{
Las relaciones intergubernamentales a raíz de la reforma del Estado en Venezuela: ¿ficción o realidad?
}

\author{
Matheus I., María Milagros*
}

\section{Resumen}

Este artículo explora el ámbito de elaciones intergubernamentales en Venezuela en sus diferentes niveles, dada la importancia que las mismas presentan en el proceso de transferencia de competencias y servicios para los Estados y los Municipios. El éxito de la descentralización dependerá de la adecuada coordinación y negociación a fin de alcanzar los objetivos planteados. Se realiza un estudio comparativo de los Estados Aragua y Carabobo y se concluye que no existe un sistema de coordinación eficaz que regule $u$ organice la nueva realidad político-administrativa de tales estados. En consecuencia, urge la ruptura con el excesivo formalismo que ha propiciado el vacío institucional, para dar paso a instituciones más eficientes.

Palabras clave: Venezuela, descentraliza, ion, relaciones intergubernamentales, coordinación.

Recibido: $98-11-28$. Aceptado: $99-\overline{09-06}$

Investigadora del Instituto de Estudios Políticos y Derecho Público. Universidad del Zulia. Email: meromero@iamnet.com. Dirección: Avenida Guajira, Núcleo Humanístico, Facultad de Ciencias Juridicas y Políticas, Bloque N. Maracaibo, Edo. Zulia, Venezuela. 


\section{Inter-Governmental Relations at the Root of State Reform in Venezuela: Fiction or Reality?}

\section{Abstract}

This article explores the area of inter-governmental relations in Venezuela at its different levels, given the importance of the same in the process of the transfer of competence and services to the state and municipal level. The success of de-centralization depends on adequate coordination and negotiation in order to reach the proposed objectives. A comparative study is made of the Carabobo and Aragua States and the conclusion is that there in no efficient system of coordination that regulates and organizes this new political and administrative reality in these states. In consequence, a rupture from the excessive formalism that has propitiated this institutional vacuum is urged, in order to achieve more efficient institutions.

Key words: Venezuela, de-centralization, inter-governmental relations, coordination.

\section{Introducción}

El objeto de este trabajo consiste en explorar lo referente a la forma, contenido, procedimiento y posibles obstáculos que enfrentan las instituciones que han sido creadas en el nivel nacional y estadal para coordinar el proceso de negociación en la transferencia de servicios.

Para satisfacer ese propósito se realiza un estudio comparativo entre los Estados Aragua y Carabobo sobre la base de leyes aprobadas en 1997 y entrevistas estructuradas abiertas, realizadas a especialistas en ambos Estados en $1998^{1}$. El articulo se organiza de la si. guiente forma: en primer lugar se discrimina el marco normativo formal que propicia las relaciones intergubernamentales, y posteriormente se hace una evaluación de las instituciones surgidas en los Estados Aragua y Carabobo, los cuales están situados en la región central de Venezuela.

\section{Antecedentes}

La Constitución venezolana vigente es el producto del Pacto de Punto Fijo que buscó darle estabilidad a la democracia constituida a partir de 1958. Uno de los principales objetivos de este pacto fue la búsqueda de un sistema político integrado, protegido de las amenazas autoritarias y del caudilismo regional. En ese entonces se hacia necesario fortalecer el cen-

1 La base de datos de entrevistas a expertos en Carabobo y Aragua realizadas en julio de 1998 forma parte de un avance de investigación del proyecto: "El Proceso de Institucionalización: Relación Estado-Municipio en el Marco de la Reforma del Estado" ${ }^{\prime}$ financiado por CONDES. LUZ, que dirige la autora. 
tralismo como medio para garantizar la estabilidad democrática, interpretando con ello que un gobierno central poderoso podía maniobrar de manera más rápida y fuerte en contra de cualquier intento autoritario que pusiera en peligro la democracia. El balance de lo sucedido entre 1958 y 1988 fue favorable para el robustecimiento de la democracia. No obstante lo que fue en principio un buen remedio, con el tiempo se convirtió en un veneno contra el propio sistema politico, entre otras razones por la pérdida del predominio de los partidos políticos como intermediarios entre la sociedad y el Estado; el exagerado centralismo que obstaculizaba el desarrollo de la sociedad civil, limitando su participación organizada; altos grados de ineficiencia administrativa y la escasez presupuestaria que da origen a graves tensiones sociales, dado el deterioro de los servicios y el retroceso de los niveles de vida de los ciudadanos (Fernández, 1993: 117 y 126).

Al constituirse el Poder Central como un único impulsor de la toma de decisiones, las relaciones con los Estados y los Municipios eran de subordinación, es decir, los Estados y los Municipios sólo existían desde el purtto de vista formal. Es por ello que luego de los continuos problemas de insatisfacción, como consecuencia de niveles de eficacia realmente bajos por parte del Poder Central, es que se impulsa una reforma del Estado para tratar de redistribuir el poder social, desde los núcleos centralizadores hacia los ciudadanos y desde el centro político-administrativo hacia la provincia (COPRE, 1989: 32).

A través de un consenso político se crea la Comisión Presidencial para la Reforma del Estado (COPRE), mediante un Decreto presidencial dictado en 1984, con el propósito de elaborar propuestas concretas para hacer más democrática la sociedad y más eficiente al Estado (COPRE, 1989:19).

Dentro de los principales objetivos de la COPRE, estuvo la necesidad de comenzar por un programa de descentralización territorial en beneficio de los Estados, dado que si bien los Estados son formalmente autónomos, según se establece en la Constitución Nacional en su articulo $16^{\circ}$, esa autonomía estaba muy comprometida en aquello que se referia a su autoridad fundamental como lo eran sus Gobernadores, la situación misma de ser de libre nombramiento y remoción del Presidente de la República dejaba muy poco margen a que esa autonomía consagrada en la Constitución jugara un papel importante en la operatividad de las actividades de los Estados.

Por esta razón era el momento de darle vida al artículo $22^{\circ}$ de la Constitución Nacional, donde se dejó abierta la posibilidad de crear una ley para elegir a los Gobernadores y por alli comenzar el proceso de descentralización, está de más decir que era muy importante la mencionada elección directa de Gobernadores, pero no lo era todo, también resultaba necesario las transferencias de competencias que tenian que hacerse a los Estados o delimitar su ámbito de actuación. En consecuencia, primero fue aprobada la Ley sobre Elección y Remoción de los Gobernadores de Estado en agosto de 1988 y posteriormente, dada su urgencia fue aprobada la Ley Orgânica de Descentralización, Delimitación y Transferencia de Competencias del Poder Público en diciembre de 1989.

Con ambos instrumentos jurídicos se abordan dos de los elementos más importantes del proceso descentralizador: por un lado, darle al Gobernador una dotación formal y efectiva de autonomía politica a través de las elecciones directas y por el otro lado, determinar y establecer los mecanismos de transferencia sobre las materlas a las cuales los Estados tendrán que abocarse.

En el artículo $2^{\circ}$ de la Constitución $\mathrm{Na}$ cional se expresa: "La República de Venezuela es un estado federal, en los términos consagrados por esta Constitución". Se definen, por tanto, las competencias que corresponden al Poder Nacional, así como los lineamientos básicos del ámbito de las administraciones municlpales, por una parte, y por la otra se dispone que "Es de la competencia de cada Estado: todo lo que no corresponda, de contormidad 
con esta Constitución, a la competencia nacional o municipal" (art. $17^{\circ}$, ord. $7^{\circ}$ ).

El artículo $136^{\circ}$ de la Constitución Nacional consagra una enumeración muy extensa de las materias cuya competencia se atribuye al Poder Nacional, tales competencias exceden a las que de ordinario han correspondido a los Estados federales. Se puede observar, el amplio desglose de competencias que le otorgó la Constitución al Poder Nacional, en algunas materias se contempla solamente el establecimiento del régimen o de la legislación básica referida a esas mate. rias. No obstante en otras, se le atribuyen la totalidad de las funciones o de los poderes jurídicos relativos a esas materias y aún se prevé la posibilidad de asumir todas las funciones cuando la Ley así lo determine, dejando a los Estados con competencias un tanto exiguas sobre las cuales trabajar.

En el articulo $17^{\circ}$ de la Constitución Nacional se encuentran expresadas las competencias de los Estados. La mayoria de las competenclas que están expresamente atribuldas a los Estados son de tipo organizativo. A este respecto, Molina (1991) considera que las competencias estadales son exclusivas cuando los Estados ejercen tanto la legislación como la ejecución de las mismas. La competencia es concurrente, cuando los diferentes Niveles Públicos poseen atribuciones sobre la misma materia.

Cuando las competencias son compartidas con el Poder Nacional éste tiene ca. rácter predominante, los Estados dentro del ámbito de las competencias concurrentes, tienen a su cargo la ejecución de la norma na* cional, el poder nacional debería en estos casos limitarse a fijar los parámetros legislativos fundamentales para darle uniformidad en tal sentido al proceso de descentralización, pero el desarrollo detallado de la norma debe corresponder a los Estados (Molina, 1991: 204).
La Ley Orgánica de Descentralización Delimitación y Transferencia de Competencias del Poder Público -LODDT- (Congreso de la República de Venezuela, 1989), vino a definir el marco de la reforma política del Estado, para reforzar el federalismo que hasta esa fecha no habla alcanzado la operatividad necesaria para su configuración.

Es por ello que cobra vida el articulo $137^{\circ}$ de la Constitución Nacional donde se expresa: "El Congreso, por el voto de las dos terceras partes de los miembros de cada Cámara, podrá atribuir a los Estados o a los Municipios determinadas materias de la competencia nacional, a fin de promover la descentralización administrativa".

A través del artículo $3^{\circ}$ de la LODDT se ratifican las competencias exclusivas ya asignadas a los Estados por la Constitución Nacional, en su artículo $17^{\circ}$. Además de éstas, según el articulo $11^{\circ}$ ejusdem se le transfieren a los Estados las competencias reservadas al Poder Nacional.

El articulo $4^{\circ}$ de la LODDT señala las competencias concurrentes entre los Niveles del Poder Público. En ejercicio de las competencias concurrentes que establece la Constituclón y conforme a los procedimientos que esta Ley señala, serân transteridos progresivamente a los Estados algunos servicios que actualmente presta el Poder Nacional. En el ámbito de las competencias concurrentes la ley como tal, no transfiere nada, sino de lo que se trata es de identificar competencias que ya los Estados compartian en forma concurrente con el Poder Nacional. "Es por ello que la novedad de la ley consiste en la consagración del mecanismo de transferencia progresiva a los Estados de aquellos servicios que actualmente presta el Poder Nacional en ejercicio de competencias concurrentes" (Ayala, 1994: 111).

Como es de observar, la probabilidad de éxito que tenga este tipo de competencias en cuanto a su funcionamiento, va a estar rela- 
cionada con el rumbo que tomen las relaciones intergubernamentales que se produzcan entre los diferentes niveles del Poder Público.

\section{Instancias formales para propiciar las relaciones intergubernamentales}

Entre algunos de los organismos creados para entablar las relaciones intergubernamentales esenciales para el desenvolvimiento normal de las relaciones Estados - República - Municipio se encuentran: La Convención de Gobernadores, el Consejo Nacional de Alcaldes, el Ministro de Estado para la Descentralización, la Comisión Nacional para la Descentralización, los Organismos Ministeriales para la Descentralización, los Organismos Regionales de Planificación y Desarrollo del Proceso de Descentralización, el Consejo Territorial de Gobierno, la Asociación de Gobernadores, los Comités de Planificación y Coordinación y la Comisión para la Reforma del Estado (COPRE).

\section{La Convención de Gobernadores} está consagrada en el artículo 190 ordinal 19 de la Constitución Nacional, en donde se señalan las atribuciones del Presidente de la República y entre otras está la de reunir en convención a todos o algunos de los Gobernadores de las entidades federales para la mejor coordinación de los planes y labores de la administración pủblica. La señalada convención es ratificada por la LODDT, sin embargo, es recomendable, en una reforma constitucional futura, fusionar tal institución con la Asociación de Gobernadores, $o$ crear otro organismo acorde con las nuevas experiencias descentralizadoras para que colabore de forma más contun- dente con el proceso de coordinación entre el Poder Nacional y el Poder Estadal.

El Consejo Nacional de Alcaldes (Presidente de la República, 1993a) cuyo objetivo fundamental es el de servir de mecanismo para la colaboración, cooperación y coordinación de politicas y acciones entre el Poder $\mathrm{Na}$ cional y el Poder Municipal, en el desarrollo del proceso de descentralización administrativa hacia los Municipios.

Los integrantes del Consejo son: el Pre. sidente de la República quien lo preside; Ministro de Relaciones Interiores; el Ministro de la Secretaria de la Presidencia; el Ministro de Es. tado para la descentralización ${ }^{2}$; el Ministro de CORDIPLAN; el Presidente de la Fundación para el Desarrollo de la Comunidad (FUNDACOMUN); un Alcalde de cada Estado designado por la respectiva Asociación o por el Consejo Regional de Gobierno; el alcalde del Municipio Libertador del Distrito Federal y el Alcalde que presida la Asociación Venezolana de Cooperación Intermunicipal (AVECI).

Sin embargo, dado el modo en que se venía presentando el proceso era necesaria una super figura que coordinara, concertara y supervisara la ejecución del proceso descentralizador, esa figura es la del Ministro de Estado para la Descentralización, tal designación fue materializada también a travếs de decreto (Presidente de la República, 1993b). La figura del Ministro para la descentralización era indispensable para establecer mecanismos de coordinación adecuados entre los ministerios para dar un mínimo de coherencia y organicidad al proceso, aunque la uniformidad no fuese posible debido a la variada situación y realidad de los Estac : (Brewer, 1994: 207). Tal y como ya se expresó esta figura desapareció.

Durante el Gobierno del doctor Caidera fue eliminado y sus atribuciones fueron asumidas por el Ministerio de Relaciones Interiores, que es el órgano superior que posee funciones referidas a las relaciones administrativas y económicas con los Estados. 
Debido a lo anterior se crea la Comisión Nacional para la Descentralización a través de decreto (Presidente de la República, 1993c), denominado: Mecanismos Institucionales para la Descentralización de la Administración Pública Nacional.

Corresponde a la Comisión impulsar, apoyar, planificar y coordinar, así como también seguir, supervisar y evaluar permanentemente el desarrollo y la ejecución de los programas de descentralización y desconcentración que corresponda ejecutar a los diferentes Ministerios, Institutos Autónomos y Empresas del Estado Nacionales (art. 4 ejusdem).

Además de la Comisión existen los Organismos Ministeriales para la Descentralización (Presidente de la República, 1993c). En todos los Ministerios, el respectivo Ministro debe designar por Resolución un funcionario con rango de Director General responsable de orientar y coordinar el proceso de descentralización en los Ministerios (articulo 7 ejusdem). En consecuencia, los Directores Generales encargados en cada Ministerio de los programas y medidas relativas al proceso de descentralización en su condición de miembros de la Comisión Nacional para la Descentralización deben actuar en coordinación con la Oficina del Ministro de Estado para la Descentralización, convirtiéndose asi en responsables del impulso, estudio, elaboración, coordinación y supervisión de los programas y medidas que, por razón de la materia, deban adaptarse y ejecutarse en el correspondiente Ministerio y en las instituciones descentralizadas que estén adscritas o dependan de cualquier forma del mismo (artículo 8).

Los Organismos Regionales de Planificación y Desarrollo del Proceso de Descentralización (Presidente de la República, 1993c) son responsables del seguimiento estadístico de la gestión intergubernamental a nivel del Estado y Municipio, son también responsables del seguimiento de las políticas nacionales en cada Estado, aparte de brindar apoyo a la sociedad civil para su incorporación y participación en el proceso de descentralización.

Existe otro organismo con objetivos muy similares a la Convención de Gobemadores, que fue creado al inicio del proceso de descentralización denominado Consejo Territorial de Gobierno (Presidente de la República, 1993d). El mismo fue concebido para mediar, colaborar y coordinar las relaciones entre el Ejecutivo Nacional y los Ejecutivos de los Estados, también para participar en el diseño de políticas y armonización de decisiones que conciernen e involucren a los distintos niveles de gobierno. El Consejo está integrado por el Presidente de la República, quien lo preside; los Gobemadores de cada uno de los Estados de la República; los Ministros del Elecutivo Nacional; el Gobernador del Distrito Federal, y una persona designada por el Presidente de la Fepública en razón de sus méritos y experiencia. En ausencia del Presidente de la República, el Ministro de Relaciones Interiores preside el Consejo.

La Asociación de Gobernadores, surge en el año 1993 por iniciativa de los Gobernadores y exhorta a la sociedad civil a hacer un frente contra la intención del Poder Central de centralizar los recursos tributarios, dado que se crea por una necesidad real que venian confrontando los Estados, es pertinente su análisis.

Su objeto fundamental es el estímulo de la cooperación interestadal con el fin de compartir experiencias y optimizar la eficiencia y efectividad de la administración regianal. La Asociación debe fomentar el intercambio de opiniones y puntos de vista entre los ciudadanos de los distintos Estados, propiciar las mejores relaciones con el Poder Central, los Municipios y la Sociedad Civil en función expresa del bienestar de la población, promoviendo la participación de los Gobernadores en el proceso de formación de leyes y definición de políticas en el nivel nacional, aparte de defender vigorosamente a los Estados en el sistema federal (Brewer, 1994:256-257). 
No pueden dejar de ser mencionados los Comités de Planificación y Coordinación establecido en el artículo 25 de la LODDT y desarrollado en el Reglamento Parcial № 3 de la misma ley. Los mismos están presididos por el gobernador y su tren ejecutivo estadal, además participan los alcaldes que integran el territorio del estado, los jefes de las oficinas nacionales y organismos regionales con jurisdicción del Estado. Su objetivo fundamental consiste en promover y asegurar la coordinación y colaboración entre la administración del Estado y los Municipios, especialmente en materia de inversiones y de prestación de servicios.

Además es conveniente señalar que a nivel nacional la COPRE tiene como función principal la concepción y la coordinación del proceso de descentralización.

Las COPRE Estadales tienen por finalidad servir de apoyo a las gobernaciones en materia de Reforma del Estado, además de servir de canal de información entre ellas y la COPRE nacional.

El profesor Luis Cosculluela (1997: 191) define a la coordinación como: "... la fijación de medios y sistemas de relación que hagan posible la información reciproca, la homogeneidad técnica en determinados aspectos y la acción conjunta de las autoridades (de distintas Entidades) en el ejercicio de sus respectivas competencias, de tal modo que se logre la integración de actos parciales en la globalidad del sistema.. Se trata de evitar la ejecución de políticas contradictorias, de evitar disfunciones, y desde el punto de vista positivo, de posibilitar acciones convergentes que potencien y optimicen los resultados del ejercicio de las propias competencias de cada Entidad".

Todos los anteriores organismos poseen funciones de coordinación, bien sea a escala nacional o estadal, de allí la dificultad para que el proceso realmente pueda ser coordinado, debido a la multiplicidad de instituciones con cabalgamiento de funciones, por tanto, es necesario eliminar esa multiplicidad de figuras con competencias similares y tratar que sólo un organismo de los mencionados $u$ otro externo a ellos sea el que se encargue de coordinar (Peña, 1995: 244).

Resulta complicado que la función de coordinar se encuentre repartida entre tantos organismos, es por ello que se producen polítcas contradictorias e inclusive la información fluye con mucha dificultad entre un Estado y otro y de esa manera no es posible optimizar los resultados generales que contribuyan al bienestar colectivo.

Para Venezuela es muy importante el proceso de descentralización, pero éste no puede conducir al divorcio de sus instituciones, sino que por el contrario, es primordial el surgimiento de un país con organismos más acertados en la toma de decisiones y que no se encuentren desarticulados entre sí, es lógico que las diferencias naturales de cada Entidad $\mathrm{Fe}$ deral les atorgue cierta independencia para tratar determinados aspectos, no obstante, existen otras cuestiones donde la coordinación juega un papel fundamental, como serían el caso de la salud y la educación.

Las diferencias son inevitables entre los Estados, pero cuando éstas se utilizan adecuadamente pueden estimular una sana competencia entre las distintas entidades territoriales. Para que las diferencias no se profundicen hasta limites en donde se comprometa la equidad social que debe animar a una sociedad democrática y abierta, se hace indispensable que el Estado de manera conjunta (Poder nacional, estadal y municipal) introduzca los mecanismos compensatorios (Blanco, 1997: 18)

La coordinación general de una materia, aparte de ser un principio instrumentable de forma voluntaria por las Entidades que participan, puede constituir una competencia de alguna de dichas Entidades, la que tiene enco- 
mendados los intereses públicos más amplios - generales en la acción a coordinar (Cosculluela, 1997: 192).

\section{Evaluación del funcionamiento de algunas instituciones que propician relaciones intergubernamentales: Casos Aragua y Carabobo}

Existen tres organismos vigentes a nivel nacional que en la actualidad poseen funciones similares, ellos son: La Convención de Gobernadores, El Consejo Territorial de Gobierno y La Asociación de Gobernadores todos con objetivos de coordinación entre los tres niveles (Nacional, Estadal y Municipal).

El problema consiste fundamentalmente en lo siguiente: la Convención de Gobernadores funcionaba cuando los gobernadores eran designados por el Presidente de la Republica, y la consecuencia práctica es que eran los subordinados de éste, por lo tanto, tal Convención era una figura con pocas posibilidades para incidir en la toma de decisiones efectiva, eso significaba que como eran de libre nombramiento y remoción del Presidente de la República sino refrendaban lo que decía éste, podian ser removidos de sus cargos. Los especialistas del Estado Aragua expresan que el tema de la descentralización nunca estuvo en agenda, lo cual reflejaba la inexistencia de voluntad politica sobre el particular. Pero en realidad lo que estaba ocurriendo es que la descentralización no formaba parte de las expectativas políticas nacionales, ni regionales, dado que el modelo político centralizado constituía un pilar fundamental del tipo de arreglos políticos prevaleciente.

En cuanto al Consejo Territorial de Gobierno pareciera que ha tenido peor destino, algunos sectores entrevistados de los Estados Aragua y Carabobo, no conocen sobre su existencia y funciones y lo confunden con otros de los tantos organismos (Comités de Planifica- ción y Coordinación) que han sido creados dentro del proceso. Por otra parte, manifiestan que el Consejo tiene un tinte muy centralista (ver supra, miembros que lo conforman).

Por último es necesario señalar a la Asociación de Gobernadores que es la que ha funcionado con mayor coherencia, sin embargo no escapa a las críticas dado que los Estados Aragua y Carabobo han sido consecuentes en sus opiniones sobre la institución debido a que los dos han sido enfáticos al admitir que han tenido aigunos logros, entre ellos la reforma de la Ley del Fondo Intergubernamental para la Descentralización (FIDES) donde se introduce un aumento importante en los montos correspondientes asignados para financiar los proyectos de los Estados. La Asociación de Gobernadores ha resultado ser un buen instrumento para canalizar los reclamos de éstos desde el punto de vista económico, pero no existen propuestas de impulso a la descentralización en cuanto a políticas que puedan convertirse en avances importantes con respecto al proceso, se evidencia por la discusión de grandes temas, sin ningún análisis crítico, por to menos que quede plasmado en actas. $\mathrm{Ha}$ sido señalada de ser como un gran sindicato que defiende los intereses de los trabajadores de las gobernaciones.

El caso ha sido que no ha funcionado como un organismo impulsor de relaciones de coordinación entre los tres niveles porque sus acciones se han orientado a otro tipo de activi. dades, válidas, como es el caso de la defensa de sus trabajadores, pero tales acciones no han sido suficientes para conectar al Poder Público entre sí y el problema continúa residiendo en que hace falta un ente que le garantice cohesión al proceso porque, de lo contrario, lo que se estaría produciendo sería un fraccionamiento del país que no va a guardar armonia político-territorial y ello podría dar la razón a los adversarios de la descentralización. La situación que se refleja en los Estados es de tal gravedad que en Aragua y Carabobo a pesar de estar tan cercanos físicamente, no fluye la información como debiera, en 
consecuencia los logros del uno son en muchas ocasiones desconocidos por el otro y viceversa, por alli puede ser medido el grado de dispersión del proceso.

Lo anterior conlleva a que el proceso de descentralización dependa más de los criterios personalistas de los gobernadores de turno, (los cuales en algunos casos pueden ser muy acertados) que a criterios institucionales serios que señalen un camino más o menos cierto por donde conducir el proceso; además, si no existen criterios claros en ese sentido, en modo alguno será posible evaluar a posteriori los supuestos aciertos o desaciertos que se vayan obteniendo. No obstante, se podría producir un entrabamiento y detenerse el proceso de reforma por no saber a ciencia cierta cómo resolver los conflictos que se presenten. "...El pais asiste a un incipiente e indetenibie proceso de descentralización para el cual no parece estar preparado, por lo que resulta imperativo realizar una revisión exhaustiva de la normativa vigente..." (Guerón y Manchisi, 1996: 38).

Los Estados individualmente han asumido ese reto de revisión y han tratado de crear sus sistemas intergubernamentales, tomando en cuenta a los Municipios, parroquias, sociedad civil, etc., debido a que los Estados están intentando una nueva concepción de la organización sobre sus territorios, en el cual ellos sean eje ordenador de procesos más no los responsables absolutos del mismo (Mascareño, 1995: 3). El proceso no sólo depende de la voluntad de los Estados sino de un concierto de voluntades donde deben estar incluidas las del nivel nacional y municipal, para lograr una coordinación más coherente, ya que "es impensable-además de ingenuo- lograr un sistema absolutamente armonioso y coordinado de gestión" (Mascareño, 1995: 2).

Para lograr una coordinación más conerente existen tres deberes fundamentales que no se deben obviar: 1) las administraciones deben respetar el ejercicio legítimo de las competencias, ejercidas exclusivamente por cada una de ellas; 2) ponderar en el ejercicio de las competencias propias los intereses públicos encomendados a otras administraciones, y 3) facilitar la información que sobre el ejercicio de sus competencias precisen otras administraciones (datos, documentos, medios probatorios). Además de estos deberes, podría impulsarse otra modalidad más activa de la coordinación, como las siguientes: a) elaborar proyectos o programas de acción conjunta; b) establecer en su propia normativa fases de intervención necesaria de otras Administraciones Públicas con intereses implicados en la acción a desarrollar, en los procedimientos de elaboración de decisiones; $c$ ) crear órganos de composición mixta (Comisiones, Conferencias) con la finalidad de establecer de una forma regular y periódica un intercambio de información recíproca y de desarrollar una coordinación más sistematizada, etc. (Cosculluela, 1997: 191-192).

A propósito de lo anterior, la Asamblea Legislativa del Estado Aragua (1997) dictó la Ley de Reforma a la Ley de Descentralización Administrativa, Delimitación y Transferencia de Actividades, Servicios y Recursos del Estado Aragua (Ley Aragua), al comprender la importancia que poseen las relaciones que deben existir entre el Estado, sus Municipios y sus ciudadanos, para poder alcanzar el éxito en el objetivo planteado por la descentralización, el cual consiste en una mayor satisfacción de las demandas colectivas.

El artículo 1 ejusdem, expresa "Esta Ley tiene por objeto establecer los criterios, normativas y mecanismos para la descentralización administrativa, delimitación y transferencia de servicios actividades y recursos del Estado Aragua a los Municipios, Parroquias, entes descentralizados tuncionalmente y organizaciones de la sociedad civil". La Ley de Descentralización de Aragua contempla la Transferencia Estado Municipio (TEM) y la Transferencia Estado Sociedad (TES), 10 cual constituye un modo de organización particular del Estado en cuestión, significando con elio que es necesario generar una especie de coordinación entre los intervinientes, para obtener una relación que sea más útil a todos los 
sectores involucrados $y$, como consecuencia necesaria, prestar un servicio más eficiente a la población que es a quien en definitiva se debe satisfacer.

Pese a la importancia de las transferenclas Estado-Municipio, la Constitución Nacional no ha establecido en ninguno de sus articulos esa posibilidad, sin embargo, es indispensable admitir la necesidad de las mismas para alcanzar un verdadero fortalecimiento del proceso descentralizador. La Ley del Estado Aragua incorpora también la novedad de la trans. ierencia de recursos hacia la sociedad, tal circunstancia es un avance importante en el ámbito de la descentralización, sin embargo, no resulta sencillo hacer proyecciones sobre una ley tan reciente, ya que todo va a depender de la forma en que se interprete y aplique la misma. Este instrumento normativo pareciera desarrollar los objetivos fundamentales del proceso de reforma, dado que estimula la descentralización Estado Municipio, pero va mucho más alla incitando también la participación de las parroquias y la del ciudadano organizado.

No obstante lo anterior, se debe evitar la repetición de esquemas, relacionados con el centralismo acentuado que se da en el nivel nacional, porque ha pasado a ser otro de los problemas que se repiten a nivel estadal y municipal. Un ejemplo está en la aplicación de la Ley del Estado Aragua que se viene analizando. El artículo 25 prevé: "...5. Un porcentaje adicional del diez por ciento (10\%) para los Municipios que transfieren y deleguen actividades, servicios y funciones a las parroquias..."

Las personas entrevistadas en el Estado Aragua expresaron que ningún Municipio de dicho estado habia realizado tal transferencia, lo cual resulta insólito dado que se les otorga un estímulo en el porcentaje del presupuesto asignado y ellos prefieren perderlo antes que descentralizar hacia las parroquias.

Ya en el año 1997este problema se reflejaba en la realidad cuando expresa Carlos Blanco (1997: 7) lo siguiente: "Presencia de vicios de la política tradicional, trasladados al plano subnacional, sobre todo en la medida en que la descentralización no está concebida actualmente dentro de un proyecto nacional en desarrollo; hay factores de clientelismo y de corrupción que se han denunciado ante la opinión pública. También se puede añadir que en algunos estados, los alcaldes y concejales de diversos municipios se quejan del "centralismo" de los gobernadores".

Es fácil darse cuenta que tales esquemas se repiten en cada uno de los niveles públicos y ya en Aragua se evidencia claramente el problema entre los Municipios y sus Parroquias, por tanto, no es sólo entre los Estados y sus Municipios respectivos que se genera el conflicto.

Es interesante analizar también la ley dictada por la Asamblea Legislativa del Estado Carabobo (1997) denominada Ley de Relaciones Intergubernamentales y del Fondo de Financiamiento de la Gestión Estado-Municipio de Carabobo (Ley Carabobo), la cual expresa su objeto en el artículo 1: "crear organismos y mecanismos que permitan armonizar y dinamizar las relaciones entre el gobierno estadal y los gobiernos municipales...", lo cual significa, la necesidad de impulsar y coordinar las relaciones entre el Estado Carabobo y sus Municipios. Al respecto se establece -prosigue el mencionado artículo- la creación de un Consejo Regional de Gobierno; el Fondo de Financiamiento de la Gestión Estado-Municipio y la coordinación de inversiones con planes concertados. El Estado cuenta con la creación de organismos específicos encargados de coordinar las relaciones intergubernamentales y de financiar la gestión Estado-Municipio.

Al comparar la Ley Aragua y la Ley Carabobo se observa que Aragua ha avanzado más, ya que involucra directamente a la sociedad organizada para que participe de manera contundente dentro del proceso, es decir, el avance de Aragua resulta evidente por las Transferencias Estado Sociedad, lo cual indica que el Gobierno Regional desea un acercamiento con el ciudadano sin intermediarios.

La Ley Carabobo en su artículo 7, numeral 5 establece la necesidad de ejercer todas las ac- 
ciones pertinentes para defender el proceso de descentralización y con ello fortalecer la capacidad de autogestión de la Región, sus Municipios y sus parroquias. Además el artículo 14 establece la necesidad de que los Alcaldes constituyan Consejos Locales de Gobierno a fin de propiciar el máximo de participación ciudadana en la elaboración de los planes y programas relacionados con las inversiones. Significa lo anterior que existe la necesidad de abrir el proceso más allá de los Estados y Municipios, pero se debe admitir que Aragua ha avanzado más porque ha resultado ser más creativo y contundente, demostrando que desea la participación de su población, por lo menos eso es lo que reflejan sus leyes.

La Ley Aragua establece en su artículo 18 una Unidad Administrativa creada por el Gobernador para promover y asesorar al Estado en el proceso de descentralización, la referida Unidad posee interesantes atribuciones relacionadas con la coordinación del proceso, pero no precisa la Ley cómo estará conformada la misma. Entre las atribuciones que posee la Unidad se encuentran: 1) mecanismos de coordinación y cooperación entre el Ejecutivo Estadal y los destinatarios; 2) diseño de políticas de armonización y acuerdos en torno de decisiones que correspondan a los distintos niveles de Gobierno; 3) promover la colaboración entre la Administración Estadal y los Municipios, así como la coordinación de actuaciones, en materia de inversiones y prestación de servicios; 4) asesorar al Ejecutivo Estadal en el diseño de políticas que permitan darle mayor participación a las instituciones de la sociedad civil para la solución de sus problemas; 5) impulsar y facilitar el proceso de descentralización administrativa, transierencia y desconcentración de funciones del Estado a los Municipios y la delegación hacia sus Parroquias...

Asimismo, la Ley Carabobo parece ser más clara en cuanto al organismo que se encargará de las relaciones intergubernamentales cuando consagra en su artículo 3 la misión fundamental del Consejo Regional de Gobier- no, la cual consiste en armonizar las decisiones que atañen a cada nivel de gobierno con el objeto de promover el bienestar, la seguridad y el mejorarniento de las condiciones de vida de sus ciudadanos, el artículo 5 dice a su vez que está integrado por el Gobernador, quien lo preside, por el Consejo de Secretarios del Ejecutivo Estadal y por los Alcaldes.

La Ley Carabobo refleja una organización más operativa para manejar las relaciones intergubernamentales, que la organización del Estado Aragua. La participación de los Alcaldes en el Consejo Regional constituye prueba fehaciente de lo anterior. En cambio, Aragua involucra al Gobernador, Asambleas Legislativas, Alcaldes, Cámaras Municipales según el artículo 13 y 14 de la Ley que se comenta. Desde el punto de vista formal las transferencias poseen un sentido más democrático debido a que intervienen todos los sectores de la vida política del Estado, sin embargo, puede suceder que el proceso se obstaculice en gran medida a consecuencia de la correlación de fuerzas políticas diferentes.

Otro aspecto digno de mencionar es el que se relaciona con la participación de las organizaciones de la sociedad civil en el Programa Especial de Inversiones, artículo 30 de la Ley de Aragua, donde en su numeral 4 se establece que es al Gobernador a quien le corresponderá establecer las áreas prioritarias hacia donde se orientará la inversión. ¿Sobre la base de cuáles criterios el Gobernador establecerá las mencionadas áreas, será atendiendo a criterios institucionales o a simples criterios clientelares? Las prioridades se deberian establecer de acuerdo a criterios objetivos que reflejen decisiones transparentes porque de no ser así, tal circunstancia generaría el efecto contrario de los objetivos que la misma Ley se ha planteado, cuando trata de convertir a la sociedad civil en la protagonista del proceso de descentralización, si esta sociedad se siente defraudada porque los criterios del Gobernador no concuerdan con los propósitos de la Ley se retirará del espacio que esa misma Ley le ha 
ofrecido y con ello se repetirá el esquema nacional con respecto a la sociedad civil y su apatía por los asuntos políticos.

En cambio en la Ley Carabobo existen criterios específicos que deben ser seguidos por los Municipios para tener acceso al financiamiento y tales proyectos serán analizados por el Consejo Regional de Gobierno, cuerpo que incluye al Gobernador, pero no depende exclusivamente de su decisión la aprobación del proyecto, sino que tienen que ser planteamientos orientados por pautas contenidas en el artículo 4 de la Ley Carabobo, entre otras podrian ser mencionadas las siguientes: fomento de actividades turísticas y de recreación; protección del paisaje, evitando la ocupación irregular de suelos; resguardo de la seguridad de las personas y propiedades..., etc.

También Carabobo ha entendido lo relevante de las relaciones intergubernamentales entre el Estado y sus Municipios y no le basta con dictar la ley que da forma a las mismas, sino que lo ratifica a través de su artículo 13 cuando establece que las Resoluciones y Acuerdos del Consejo Regional son de obligatorio cumplimiento y sus actuaciones representan el máximo nivel de concertación entre el gobierno estadal y el municipal para el logro de sus objetivos.

\section{Conclusiones}

El objeto de la presente investigación fue el análisis de la forma, contenido, procedimiento y los posibles obstáculos que enfrentan las instituciones nacionales, estadales y municipales creadas para la coordinación de estos tres niveles de gobierno. El problema que se observa es la existencia de una multiplicidad de organismos con atribuciones idénticas que funcionan de forma muy deficiente, o en el peor de los casos no funcionan y los Estados no diferencian unos organismos de otros porque son demasiados y muy parecidos. Un ejemplo sería el caso de los Estados Aragua y Carabobo donde existe confusión en relación con las instituciones nacionales (Consejo Territorial de Gobierno con los Comités de Planificación y Coordinación).

En consecuencia, es indispensabie que la coordinación, el sistema de información y ei control marchen uno al lado del otro e involucren a los diferentes niveles del Poder Público. Resulta necesario eliminar tantos organismos coordinadores para encontrar una salida institucional que restrinja la dispersión del Estado Nacional, sería conveniente analizar la posible creación de un organismo menos pesado burocráticamente, diferente a los tantos ya existentes que se encargue efectivamente de coordinar y evaluar para evitar con ello generar un caos.

Esa nueva institución que se sugiere deberá cuidarse de repetir los problemas y vicios que los múltiples órganos creados para cumplir la misión de coordinar han reproducido, como por ejemplo evitar ser centralizadores per se, sin abdicar de modo irracional a todo cuanto los Estados propongan; además debe existir la suficiente voluntad política y normativa por parte de los tres poderes para lograr la consagración de tal ente coordinador $u$ organizador para que se convierta en el verdadero conductor del proceso.

A la par debería funcionar un órgano contralor que lejos de entorpecer la gestión, ejerza la autoridad necesaria de la fiscalización del proceso de descentralización que ha venido cosechando importantes avances y resultaría nocivo dejar que se pierda en la apatía $y$ el desorden.

Gordillo introduce un aspecto que es fundamental para evitar la creación innumerable de instituciones: "La cuestión, entonces, reside en que las normas del sistema no deben ser elaboradas unilateralmente por nadie, en la oscuridad de una trastienda sino que deben ser elaboradas a la luz del día, en la discusión y debate públicos, con la participación e intervención creadora y crítica de todos los ciudadanos, para que respondan fielmente al pensamiento de la sociedad y reflejen sus aspiraciones verdaderas y reales; de modo que cuenten entonces 
con el respaldo de la adhesión y el consenso comunitario, que son los que luego asegurarán el efectivo cumplimiento del sistema y no la creación del parasistema"3 (Gordilio, 1982: 87-88). Expresa el autor que las normas deben reflejar las aspiraciones reales y verda. deras de la sociedad para contar con su adhesión, para que de esta reforma surja un nuevo ciudadano que posea la convicción firme y el respeto por las normas y sus instituciones, de no ser asi, la norma y las instituciones que surjan de ellas no serán eficaces porque los ciudadanos no se verán reflejados en ellas.

Es fundamental continuar explorando el proceso de descentralización para ir detectando los obstáculos que van generándose, como serian la creación de instituciones centralizadas que interfieran en el avance del proceso, es importante que las que surjan resulten verdaderos eniaces entre los diferentes niveles del Poder Público, debido a la necesidad de impulsar un verdadero proceso de reforma del Estado.

Los Estados Aragua y Carabobo están haciendo los intentos pertinentes en materia de relaciones intergubernamentales sería conveniente tornar su ejemplo por parte del Estado Central y los Estados que todavía no hayan dictado la normativa pertinente.

\section{Bibliografía citada}

Ayala, Carlos (1994). Leyes y Reglamentos para la Descentralización. Caracas: Editorial Jurídica Venezolana. Caracas.

Blanco, Carlos (1997) El Proceso de Descentralización en Venezuela (análisis crítico). Working Papers Series, Ban- co Interamericano de Desarrolio, Washington, D.C.

Brewer, Allan (1994). Informe sobre la Descentralización en Venezuela 1993. Memoria del Dr. Allan R. Brewer Carias Ministro de Estado para la Descentralización. Editorial Arte. Caracas.

COPRE (1989). La descentralización. Una oportunidad para la Democracia. Volumen 4, Caracas: Editorial Arte.

Cosculluela, Luis (1997). Manual de Derecho Administrativo. Octava edición. Madrid: Editorial Civitas. Madrid.

Fernández, Julio (1993). "Alcances y Perspectivas de la descentralización políticoadministrativa en Venezuela" en Contribuciones. Buenos Aires: Konrad-Adenauer-Stiftung Centro Interdisciplinario de Estudios sobre el Desarrolio Latinoamericano. Buenos Aires.

Gordillo, Agustín (1982). La Administración Paralela. Madrid: Cuadernos Civitas.

Gueron, G. y G. Manchisi (1996). "La descentralización en Venezuela: Balance de un proceso inconcluso", en A. Alvarez (coord.) El Sistema Político Venezolano: Crisis y Transformaciones. UCV. Caracas.

Mascareño, Carlos (1995). Negociación y coordinación entre niveles de gobierno: un imperativo de la descentralización. COPRE. Caracas.

Molina Vega, José (1991). "La competencia constitucional de los estados en el proceso de reforma del Estado", en EI Nuevo Derecho Constitucional Venezolano. Memorias del Primer Congreso Venezolano de Derecho Consciudadanos y tiene que buscar otros rumbos distinto a los plasmados en el sistema formal. 
titucional. EDILUZ. Maracaibo. Venezuela.

Peña Solis, José (1995) Lineamientos de Derecho Administrativo (Vol. I: La Organización Administrativa Venezolana). Facultad de Ciencias Jurídicas y Políticas. Universidad Central de Venezuela. Caracas.

\section{Documentos citados}

Asamblea Legislativa del Estado Aragua (1997). Ley de Reforma a la Ley de Descentralización Administrativa, Delimitación y Transferencia de Actividades, Servicios y Recursos del Estado Aragua. Gaceta Oficial Extraordinaria del Estado Aragua No. 524 del 24 de abril.

Asamblea Legislativa del Estado Carabobo (1997). Ley de Relaciones Intergubernamentales y del Fondo de Financiamiento de la Gestión Estado - Municipio. Gaceta Oficial Extraordinaria del Estado Carabobo No. 738 del 16 de septiembre.

Congreso de la República de Venezuela (1961). Constitución de Venezuela. Caracas

Congreso de la República de Venezuela (1989). Ley Orgánica de Descentralización, Delimitación y Transferencia del Poder Público. Gaceta Oficial No.
4.153 Extraordinario del 28 de diciembre de 1989.

Presidente de la República de Venezuela (1993a). Decreto sobre el Consejo Nacional de Alcaides. Decreto No. 3.169. Gaceta Oficial No. 35.320 del 19 de noviembre de 1993. Caracas.

Presidente de la República de Venezuela (1993b). Nombramiento del Ministro de Estado para la Descentralización. Decreto No. 3.032. Gaceta Oficial No. 35.229 del 9 de junio de 1993. Caracas.

Presidente de la República de Venezuela (1993c). Reglamento Parcial No. 2 de la Ley Orgánica de Descentralización, Delimitación y Transferencia del Poder Público, sobre los Mecanismos Institucionales para la Descentralización de la Administración Pública. Decreto No. 3.085. Gaceta Oficial No. 35.268 del 5 de agosto de 1993. Caracas.

Presidente de la República de Venezuela (1993d). Reglamento Parcial No. 3 de la Ley Orgánica de Descentralización, Delimitación y Transferencia del Poder Público, sobre el Consejo Territorial de Gobierno y la Organización Intergubernamental para la Descentralización. Decreto No. 3.104. Gaceta Oficial No. 35.273 del 12 de agosto de 1993. Caracas. 